Statisticg of the Hospetal.

The statistics now to be reported consist of 33,066 operations performed during the four years 1926-29;31,301 operations were under general anaesthesia, and the remaining 2,765 were conducted under some form of local anaesthesia. According to the hospital recards there were 55 respiratory complications with 23 deaths.

\section{Methods of Induction.}

Before going into a detailed analysis of these 55 cases a few words giving the pre-operative routine might not be out of place; probably about 65 per cent. of the patients would have a preliminary injeetion of $1 / 6$ grain of morphine sulphate, combined with $1 / 150$ grain of atropine sulphate. We rarely use large doses of morphine. Great care is exercised in exeluding from operation patients with a cold or coryza, even if afebrile. In cases with a history of recent respiratory trouble or tonsillitis operation is postponed for two to four weeks.

More than half of this series received ether dropped upon a thick cotton fabric supported by a wire frame; a mixterre of two parts of chloroform with three parts of ether was added in any operation where ether would $\mathrm{no}^{+}$ induce sufficient relaxation by itself. Nitrous oxide and ethylene were administered by MeKesson machines; one in six would be a rough estimate of gas anaesthesia. Postoperative ward treatment varied widely according to the individual clinician. The gravity of the operation ranged from excision of a sebaceous cyst, and buief dental extractions, to thousands of appendicectomies and herniotomies, and severe operations upon patients with grave renal or cardiac conditions. The ages of the patients ranged from 4 days to over 90 years.

One feature which emerges most prominently when first looking at the morbidity of this series of cases is the number of patients with additional pathological changes to that for which the operation was designed to relieve. Kipling states: "Indeed when you come to think of it, had the British Army consistently waited for reserves in all its little affairs, the boundaries of our Empire would have stopped at Brighton Beach."

Nature of Cases with Ensuing Respiratory Complications.

Of the 55 patients with respiratory complications in this report, 13 had sequels of a minor nature, 7 infarcts, and there were 6 cases of pleurisy; the remaining 42 suffered from pneumonic processes. These 42 cases included 9 emcrgency operations; 16 patients (including 7 of the previously mentioned) had marked elevation of the pulse, temperature, and respiration at the time of operation. Nime patients were aver the age of 60 , and in 23 (more than half) the operation involved the gastro-intestinal traet, including herniotomies.

Another interesting point is the gravity of sepsis at the time of operation; 23 of the 42 patients with major complications died, and at the time of operation 19 of these 42 had gross sepsis. Of these 19 patients with sepsis, 14 died (73 per cent.). Twenty patients out of the 55 originally mentioned were first-elass operative risks with one death; this may be compared with the 35 substandard patients with 22 deaths.

In 1929 of 1,772 abdominal operations (excepting 242 thyroidectomies), there were 6 respiratory complications with two deaths; both patients who died were over the age of 70 , and the operations were emergency ones. In the same hospital in 1922, Dr. H. Morrison ${ }^{8}$ reported upan 408 patients operated on for appendicitis, with one death from preumonia. Broadly speaking, this report agrees with the ratio of respiratory lesions given for 1929-a morbidity of 6 in 1,772 cases.

The sexes were approximately equally affected in this series. Some writers have stated that respiratory complications aecur more frequently in males than females, owing to the interference with the abdominal type of breathing rather than with the thoracic type characteristie of women. As regards age, each decate over 40 adds to the operative risk. Fair comparisons of the type of operation are difficult to establish. An American writer has stated that post-operative pulmonary complications occur in 14.8 per cent. of stomach operations, and in 5 per cent. of operations upon the gall-bladder, averaging altogether 7.7 per cent.

No definite conelusion can be reached as to the influence of the length of operation. A number of the poor risk patients had short anaesthesia periods and suceumbed. It might be said, however, that the shorter the time under a general anaesthetic the less interference would there be with the vital processes of the body. Gas anaesthesias carried with them a higher ratio of pulmonary lesions than ether, but in many instances gas anaesthesia was given in preference to handicapped patients. Neuhoff ${ }^{9}$ reports 500 necropsies following surgical operations. Pneumonia was diagnosed previously in 81 cases and found after death in 51 subjects, or 60 per cent. He states also that " a diagnosis of post-operative pneumonia in sick patients is fraught with difficulty, and the classical physical signs of pneumonia do not prove its presence in serious post-operative conditions." In addition, Neuhoff found pneumonia a much more common cause of death in elean wounds than in infected wounds; 11 per cent. in the former, 1.5 in the latter.

\section{Theory of Lung Infection.}

The splinting of the abdominal muscles due to pain in the wound and tight binders causes more or less circulatory stasis in the bases of the lungs. This area of stasis is invaded by infection passing up the lymphatics through the diaphragm. Collyros believes that atelectasis and pneumonia are different phases of the one process. $\mathrm{He}$ states: "In the atelectatic portion of the lungs the vessels exude a sticky secretion. This secretion prevents the passage of air, and consolidation follows; after cansolidation infection follows so easily."

\section{Conclustons.}

1. Post-operative pulmonary complication is a serious hazard to recovery; 40 per cent. of the patients died in this series. Of 13 patients with elevation of pulse and temperature at the time of operation 11 died ( 84 per cent.).

2. Taking into consideration the number and gravity of modern surgical procedures, pulmonary complications following operations are less numerous than might be expected. In this series 15 per cent. of the patients were 70 years old, and 21 per cent. had elevation of the pulse, respiration, and temperature at the time of operation.

3. Sepsis (gross) at the time of operation is a greater risk than post-operative pneumonia.

4. Careful selection of patients, and pre-operative measures with equal attention to the matter of after-care, will keep the incidence of respiratory lesions down to the minimum, until such time as a definite cause is known for this dreaded operative sequel.

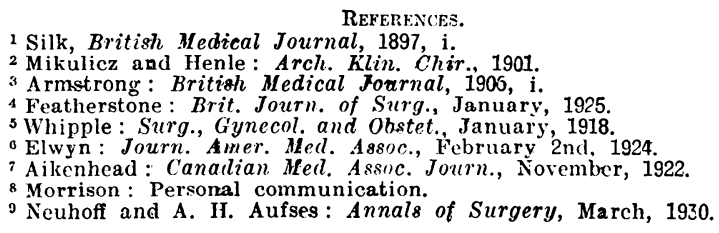

\section{THE INFLUENCE OF IACTATION ON OVULATION AND OESTRUS. \\ ix}

\section{J. T. CUNNINGHAM, M.A., F.I.S.}

Acconding to Crew and Mirskaial oestrus and ovulation occur in the mouse within twenty-four hours of parturition, and if no fertilization then takes place there is no second oestrus for an interval of twenty to twenty-five days, which is the normal duration of lactation. This interval, called the lactation interval, cannot be appreciably lengthened by prolonging the actual lactation by means of supplying new litters of young, but on the other hand, if the original litter is removed at a shorter interval-for example, seven or fourteen days after birth-oestrus recurs on the second to fourth day after such removal. They state that, according to the evidence of experiment, lactation causes the 
corpora lutea of the first post-partum oestrus to persist, and that these corpora lutea inhibit oestrus during the lactation interval. The theoretical explanation proposed is that the stimulus of sucking acts on the anterior lobe of the pituitary, and that the excess of pituitary secretion so produced causes the persistence of the corpora lutea.

The weakness of this theory is that there are many mammals in which lactation does not inhibit cestrus. In the ungulates-the cow, mare, and sow-according to Parkes, lactation has no effect on the recurrence of the oestrous cycle, and therefore presumably on ovulation. In the human species the occurrence of menstruation during lactation seems to be quite common, but not without exception. In cases where there is no succession of short oestrous cycles the question of the effect of lactation does not arise: for example, in the dog pregnancy lasts about two months, and is followed by lactation for about the same period, and there is no recurrence of oestrus during all this time; but oestrus is also absent for a similar period when no pregnancy or lactation occurs.

The case of the ferret, recently investigated experimentally by Hammond and Marshall, is in strong contrast to that of the dog, though both animals are carnivores. Oestrus in the female ferret is marked by a conspicuous feature-namely, great swelling of the labia of the vulva. Ovulation occurs only after copulation and, in the absence of this, oestrus continues till the end of the breeding season. The duration of pregnancy is forty-one or fortitwo days, and the recurrence of oestrus after parturition depends entirely on lactation. When the young were killed immediately after birth oestrus began nine days later, but while lactation continued there were no signs of it. Moreover, during lactation the corpora lutea do not remain large, as in the rat, but rapidly atrophy, as in the rabbit, from which it would appear that the influence of lactation in suppressing oestrus does not act through the medium of the corpus luteum.

Another instructive contrast is afforded by the rat $\mathrm{cr}$ mouse and the guinea-pig. Both genera are polycestrous, the cycle in the rat occupying five to six days, in the guinea-pig about sixteen. In the guinea-pig there is no lactation interval; there is, as in mouse or rat, an immediate post-partum oestrus, followed by a second at the normal interval of sixteen days, during lactation. As the suppression of oestrus only occurs in the mouse when more than two young are suckled the absence of oestrus-suppression in the guinea-pig has been attributed to the smaller number and greater maturity at birth of the young in this animal.

According to the results of $O^{\prime} D^{\prime}$ onoghue ${ }^{2}$ and Hartman ${ }^{3}$ the difference between the marsupials Dasyurus and Didelphys virginiana is similar to that between the dog and the ferret. The former is monoestrous, and ostrus is absent not only during the period of lactation but during the corresponding period when there are no young in the pouch. In Didelphys virginiana, on the other hand, in the absence of pregnancy oestrus recurs every twentyeight days, but is suppressed during the whole of lactation, the young remaining in the pouch about fifty days. But if the young are removed from the pouch and destroyed oestrus returns ten to fifteen days later.

It is not possible to discuss details at greater length in such an article as the present, but enough has been stated to prove that there is no general correlation between the stimulus of sucking and the suppression of oestrus, as is assumed by the theory of Crew and Mirskaia. This correlation occurs in the mouse and rat, in the ferret, the rabbit, and the Virginian opossum, but it is absent in cow, mare, goat, pig, and frequently, if not always, in the human species. It seems to me that the really significant correlation is between the suppression of ocstrus and the condition of the newborn young. In those cases where oestrus is inhibited the young are naked, immature, and kept for the greater part of the time cnclosed in a warm nest in close contact with the mother. In the other cases where oestrus occurs during lactation, as in the cow and the guinea-pig, the young are born covered with hair and able to run almost at once. If the inhibition of oestrus were due to the absorption of soluble substances by the mother from the bodies of the roung, either from the mouths of the latter through the teats, or from skin to skin, the correlation between the nidicolous immature condition of the young and the suppression of osstrus during lactation would be explained, while on the theory of the stimulus of sucking, since this stimulus occurs in the cow as in the mouse, there is no reason for the difference between the two in respect of oestrus during lactation. 'The case of Didelphys is especially important, for here the young are born after a gestation of only thirteen days in an early foctal stage of development, and are transferred to the pouch, where they become permanently attached to the teats. The skin within the pouch is naked, vascular, and glandular, and removal of the roung from it has the same effect with regard to oestrus as removal of the foetuses from the uterus in higher mammals. The stimulus of sucking maintains the process of lactation in all cases, whether in the cow or the opossum, and it has been shown in the opossum and in the rabbit that the stimulus determines secretion, not in the whole system, but in each gland individually; but it is improbable that it affects the occurrence of oestrus.

How the hormones supposed to be absorbed on the theory 1 have suggested could affect the recurrence of oestrus, whether by acting on the corpora lutea or on the pituitary, is a matter for future investigation, but it may be mentioned that in most cases there is reason to believe that substances absorbed from the foetuses in the uterus determine the persistence of the corpora lutea. Considering the atrophy of the latter after abortion, it is a question whether it is the function of corpora lutea to maintain pregnancy, as frequently stated, or the effect of pregnancy to maintain the corpora lutea.

${ }^{1}$ Crew, F. A. E., and Mirskaiarerevces.

Quart A. E., and Mirskaia, L.: Lactation Interval in the Mouse, O.Dont. Journ. Exper. P'hys., June, 1930, vol. xx, No. 2 . Relation of Corpora Lutea Thereto, Quart. Journ. Micr. Sci., 1911, 57. 1923, varl: Oestrous Cycle in the Opossum, Amer. Journ. Anat.,

\section{fftentaranda:}

\section{MEDICAL, SURGICAL, OBSTETRICAL.}

\section{FOREIGN BODY IN THE CAVERNOUS SINUS.}

A cASE similar to the one here recoraded was reported by J. F. I. King in the British Medical Journal of October 30th, 1926, where a woman fell on her face and struck her head against some wood outside her cottage door. Six pieces of wood were found in the cavernous sinus, and she died of meningitis, orbital abscess, and a cerebral abscess in the right temporal lobe. In the present case there was only septic meningitis.

A man, aged 40, was admitted into the General Hospital, Colombo, under the care of Dr. Lucian de Zilwa, with a history of fever of ten days' duration.

Some time ago he was walking in his garden when a coco-nut branch fell on his head, causing a small wound just above the inner canthus of his left eye. He was treated at the Victoria Memorial Eye Hospital, where the surgeon extracted a small piece of splinter and treated the external wound. In a few days he developed fever and headache, and later became very drowsy. $\mathrm{He}$ was then transferred to the General Hospital. Examination revealed a penetrating wound above the inner canthus of the left eye. He was semi-comatose, and did not answer any questions. There was bilateral proptosis; the pupils were dilated and inactive, the left being more dilated than the right. There was no paralysis. The lungs, heart, and abdomen were normal. Further examination could not be carricd out as the patient died within two hours of admission.

Post-mortem Examination.-On opening the skull cvidence was found of septic meningitis. There was a thin layer of pus over both hemispheres anteriorly-more marked on the left side. The left cavernous. sinus was occupied by a thrombus, in which were embedded two pieces of splinter. One picce measured $1 / 2$ inch by $1 / 5$ inch; the other was smaller. Points of yollow material in the thrombus had been caused by suppuration. "There was also a thrombus in the right cavernous sinus. Extravasations of blood and minute pieces of splinter were found along the floor of the left orbit. The eyeball was not damaged, nor were the orbital muscles. There was no fracture of the bones of the orbit.

The absence of damage to the eyeball was remarkable. The splinters must have becn driven with considerablo 